\title{
Customer interactions on social media and their impact on trust and loyalty: the moderating role of product learning
}

\author{
Ismet Esenyel $^{\mathrm{a}}$ and Mete Girgen ${ }^{\mathrm{a}}$
}

${ }^{a}$ Girne American University, Cyprus

\begin{tabular}{l}
\hline C H R O N I C L E \\
\hline Article history: \\
Received: April 5, 2019 \\
Received in revised format: April \\
192019 \\
Accepted: May 2, 2019 \\
Available online: \\
May 5, 2019 \\
\hline Keywords: \\
Social media \\
Customer interaction \\
Customer trust \\
Customer loyalty \\
Hotel industry \\
Tourism and hospitality
\end{tabular}

A B S T R A C T

This research examines the customer engagement on social media platforms in the tourism industry and its effect on customer loyalty through the mediated effect of customer trust. Furthermore, the moderating role of product learning is investigated on the hypothesized relationships. Data was collected from guests in 5 stars hotels in Kyrenia region in Northern Cyprus. In this study, out of the 459 collected surveys, only 419 were analyzed due to missing or incomplete data. The analysis conducted here followed the two step approach for structure equations modelling. Firstly, a confirmatory factor analysis was appraised to prepare data for structural model. Then the structural model helped shape our direct hypothesis testing, before analyzing the mediating and moderating impacts. The data provided evidence to link customer interactions on social media with trust and loyalty (Hypotheses 1-3) while trust revealed a mediating effect between interaction and loyalty. Finally, product learning did have an empowering impact on the relationship between interaction and trust.

\section{Introduction}

In the hospitality industry recently constructed business reality, consumers' usage of social media has been observed as a major change in the industry revolutionized social dynamics. In particular, consumers have been resorting to virtual communities through social media sites or weblogs by sharing photos, videos and stories. As a result, tourists are leaving behind them a digital footprint of their experiences in the form of comments, reviews and opinions (Bilgihan et al., 2013). Such signs left behind by customers in the tourism sector are treated as trustworthy source of information by potential future buyers (Yoo et al., 2009).

Understanding a social network involves grasping the identity of actors connected by a cluster of relationships (Brass et al., 1998). Such relations, that connect actors with each other, are varied by type and magnitude. Grabner-Kräuter (2009) divides these relationsships as befriending or affiliating that are distinct from trading, financial or information exchange based connections. Further, applying these social networks to computer based mediums has been proposed, where an electronic network is described as self-organizing formation which is aided and supported into existence by a computer-based channel of interaction (Wasko \& Faraj, 2005). Social networks supported by computer applications are suggested * Corresponding author.

E-mail address: mete_girgen@hotmail.com (M. Girgen) 
to have repercussions for business and private lives alike (Wellman et al., 1996). It comes as no surprise then that hotel guests who use these electronic mediums and participate in activities such as, posting photos, writing reviews or making comments are essentially playing a fundamental role in upholding a social network of users.

Quintessentially, internet services that provide users the capacity to enlist by creating public, private, or half-public personal accounts though which they can interact with other users of the service and make connections with them represent what is referred to as "social network sites" (Boyd \& Ellison, 2007). Further, research into social network services has established that using these social networks does influence created knowledge which in turn has an effect on using different services for executing transaction, sharing information or media-rich messaging (Kleijnen et al., 2009). As such, knowledge creation among potential hotel guests through using social media does influence the use of social media creating a knock on effect on other new customers.

With the advent of travel 2.0 accompanying web 2.0, social networks have made strides in cementing a place in the tourism and hospitality industry (Huang et al., 2010). Tourists engage in activities to look up information from others through posted comments or shared experiences and reviews that are openly available on social media sites (Chung \& Koo, 2015). For example, sightseeing has been mentioned as a touristic activities that is highly prone to information available on social media sites by people who visited these places (Iryo et al., 2012). The users on these platforms are inclined to stay by these knowledgesharing behaviors as opposed to tourists who are not using these social media sites who might have privacy or security concerns (Huang et al., 2010). Moreover, the use of mobile phones in social networks allow for instant connections to be made that are based on experiences shared by hotel guests resulting in more emphasis on understanding the use of social media for tourism businesses (Tussyadiah, \& Zach, 2012). Consequently, the importance of social media use among tourist for decision makers in the tourism industry provides the rational for focusing on understanding social interaction and its effects on loyalty and trust that is investigated in this research.

\section{Theoretical development}

\section{1 interaction}

Interaction represents a socially embedded phenomenon that enhances a sense of an online community within consumer groups. Predating social media online communities it has been noted that customer interactions play a role in formulating evaluations by customers about the quality of the service (Howat et al., 1996; Mcdougall \& Levesque, 1994; Wakefield et al., 1996). Within the hospitality and tourism sector, some scholars have proposed a model for customer interaction outcomes from a service quality perspective, those were postulated to include: conduct, expertise, problem solving, equipment, ambient conditions, waiting time and value (Caro \& Roemer, 2006). On the other hand, personal interactions were found to impact on satisfaction and loyalty (Chen et al., 2013). Additionally, prolonged social dealings that include interactions between two or more parties were recognized as antecedents of building trust (Holmes, 1991; Wang, \& Emurian, 2005). Consequently, the authors propose the following:

$\mathrm{H}_{1}$ : Customer interaction on social media platforms will have a significant effect on customer loyalty to the hotel.

$\mathrm{H}_{2}$ : Customer interaction on social media platforms will have a significant effect on trust in the hotel.

\subsection{Trust}

According to Chaudhuri and Holbrook (2001), when consumers perceive a service provider to be trustworthy, they are comfortably confident that a seller is providing a service that meets its claimed functionality or value. Such an idea reflects situations where consumers find themselves in situations of asymmetrical information and fear being exploited. In this context, displaying trust in service providers reduces uncertainties and anxieties in customers' perceptions and enhances their comfortability with the 
service provided (Chiu et al., 2010; Pavlou et al., 2007). Interacting on social media is a continuous process that is thought to be involving information dissemination among groups' members about the related services. The more shared information available for social media potential hotels guests, the less information asymmetry they feel. Thus, theoretically we argue that social media interactions lead to higher levels of trust. Similarly, when potential customers develop a trusting attitude towards a service provider it enables a sense of loyalty to emerge. Based on the arguments presented in this section we hypothesize the following:

$\mathrm{H}_{3}$ : Customer trust in hotels does significantly affect the loyalty among customers.

$\mathrm{H}_{4}$ : Customer trust in hotels plays a mediating role in the relationship between customer interaction and customer loyalty.

\subsection{Product learning}

Social media interactions among customers allude to positive special features or less satisfying experiences of hospitality services experienced. Through offering advice to other social media users on how to deal with problems in the service they receive or how to make the most of a certain experience indicates a customer's product-related knowledge (Lerner \& Tirole, 2002). This allows a certain group of social media users to enhance their reputation by becoming influential opinion leaders (Jeppesen \& Molin, 2003). This affects the perceived value of services provided which has a role to play in shaping customer's attitudes or behaviors (Kim et al., 2011). It has been reported that consumers do seek online communities' active engagement to enhance their knowledge base about certain products of interest (Hsu \& Huang, 2011). Moreover, social media users who believe that some learning targets were achieved through using social media are inclined to continue using these platforms for future knowledge gains regarding products and services (Huang \& Chen, 2018).

Here we suggest that customer perceptions regarding the opportunity for such knowledge gains regarding tourism and hospitality services will have a determining impact on the relation between customers' interaction and trust in the service provider. As such, we hypothesize the following:

$\mathrm{H}_{5}$ : Product learning has a moderating effect on the relation between customer interaction on social media platforms and customer trust in the hotel.

\section{4 theoretical model}

Based on critically reviewing the related literature, the authors propose the following model to be examined empirically by the aforementioned set of five hypotheses.

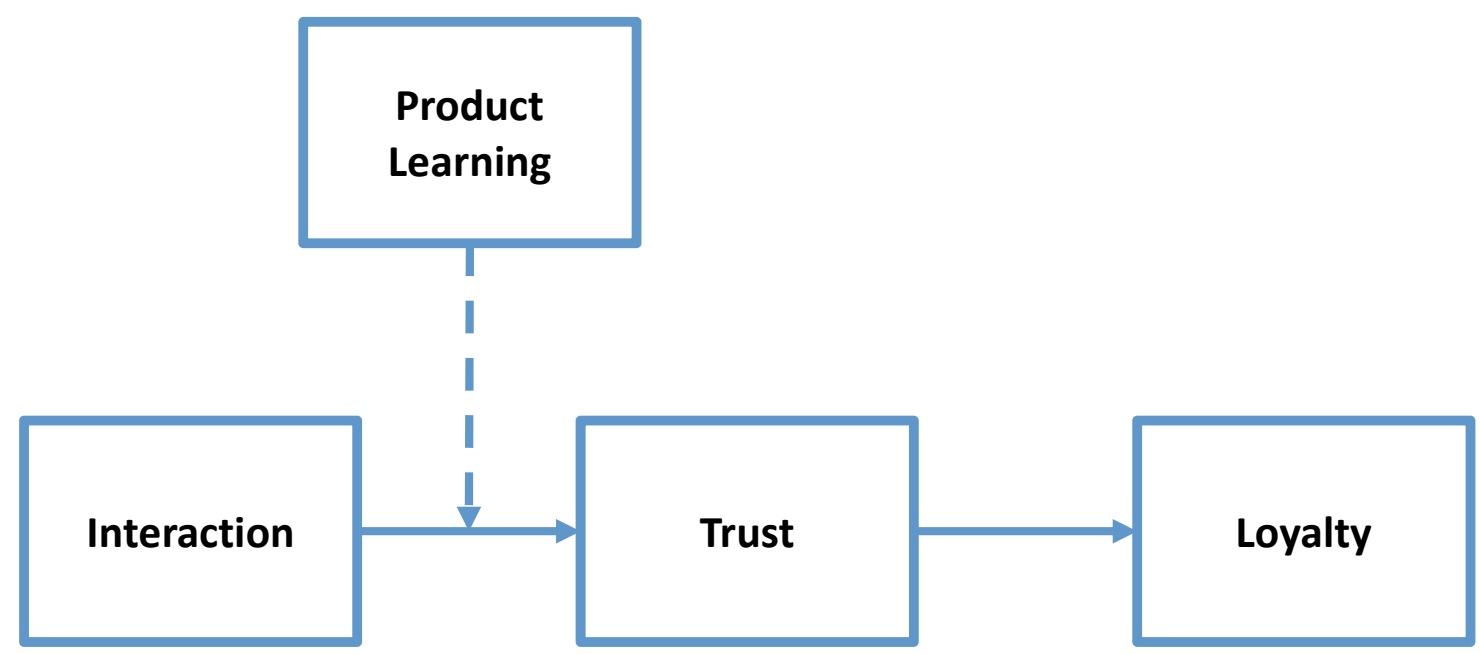

Fig. 1. Theoretical model of the study 


\section{Methodology}

\subsection{Study design}

The research design employed in this research was based on field study whereby customers from five stars hotels in Kyrenia- Cyprus were approached for participating in this study by the author. The sampling method used was simple convenience sampling. Using this technique aimed at reducing the bias in the pool of respondents as well as eliminating potential errors associated with other forms of sampling. Using this method gave each hotel guest an equal chance to participate in the study reported here. In accordance with scholarly tradition of rigorous survey design, the authors opted for the survey to adopt an anonymous design. This helps in reducing the margin for biased responses from the respondents. Moreover, ethical norms of survey design have been observed. The authors informed participants of the purpose of the survey study and were given assurances that data collected for this research will remain only in the hands of the researcher himself. Also, hotel staff members were acquainted with the researcher purpose and authenticity in case participants wanted to check the legitimacy of data collection in these hotels.

\subsection{Measurement}

Customer social media interaction was measured by three items adopted from Harrigan et al. (2017). Customer behavioral loyalty was measured by five items adopted from Zeithaml et al. (1996). Product learning was measured by four items based on the work accomplished by Nambisan and Baron (2010). Trust was measured using three items based on Habibi et al. (2014) adopted scale.

All items were measured on 5 pion Likert scale ranging from one to five. $(1=$ Strongly Disagree, $4=$ Disagree, 3 = Neither Disagree Nor Agree, 4 = Agree, 5= Strongly Agree).

\subsection{Data collection}

The self-administered survey used here was collected at the premises of all 5 stars hotels in Kyrenia. Data collection took place over 10-week period from December 2018 to March 2019. Due to financial, time and personnel constraints convenience sampling was deemed an appropriate fit for this research. Such a sampling method has been implemented in the past by scholars in the tourism and hospitality field (Chen et al., 2013), in light of similar limitations placed on researchers. Hotel guests who were showing or indicating their availability to participate in this research were asked to fill in the survey. By the end of this period, 459 responses were collected. After dropping out incomplete questionnaires the number dropped down to 419 representing $91 \%$ of total number of research participants.

This participation percentage is on the high side among social scientists in general; however, in the tourism management field some researchers have reported $95 \%$ of active response rate (Chen et al., 2013). Such a high response rate might be justified by the fact that using the data collection method allows researchers to approach all hotel guests and give those show interest in participation a questionnaire to scan before they decide to complete it. Thus, the response rate from distributed questionnaires are higher than other study designs. The questionnaire was measured for its reliability and revealed satisfying results.

\section{Analysis and findings}

The use of statistical analytic tools has aimed at meeting the study objective of testing the theorized hypotheses. The authors first looked at the collected data through descriptive analysis tools, analysis of means, etc. in order to assess the involvement of the attributes of the constructs on the adopted scales based items, the authors opted to conduct factor analysis that helped determine the underlying factor structure associated the constructs studied. Gathered data was analyzed using two statistical packages SPSS V.22 and AMOS V.24. 
This analysis follows the recommended guidelines set by Gerbing and Anderson (1988). First a measurement model of the study variables was assessed and the second step involved testing the structural model. Using the maximum likelihood estimator, a confirmatory factor analysis (CFA) was evaluated. The assessment relies on how well the manifested variables mirror the theorized latent variables. Followed by employing structural equation modelling (SEM) techniques to test validity of the constructs and goodness-fit indices for both the measurement and the structural models. This eventually led to examining the relationships among the study variables.

\subsection{Descriptive analysis}

The gathered dataset after dropping out missing and incomplete answers was 419 responses. With regards to the gender distribution 58\% were male and $42 \%$ were female. Out the 419 research participants more people from the age group 41-50 (33\%) participated in this research, followed 31-40 age group (29\%). Educational level varied among respondents as $56 \%$ held a university degree while $23 \%$ reported high school education. The main sources of choosing a place of stay were "word of mouth" (28\%) "Travelling agent recommendation" $21 \%$ "surfing the internet" $20 \%$.

\section{2 validity and reliability}

Before starting the two step approach for structure equation modeling, the dataset was examined dimensionality, reliability and validity. The objective was to understand the determinant factors presented by the data. As such a factor analysis was carried out, the results of Cronbach's alpha were above the threshold defined by Nunnally (1967) at 0.70 . Moreover, cumulative variance explained values indicated that the adopted scale was reliable for measuring interaction, product learning, trust and loyalty. As a result four groups of items were grouped together representing the latent variable that would go further statistical examination. Once the latent variables have been statistically shown to include the items that were theorized to formulate them, a confirmatory factor analysis has been developed to test the measurement model of interaction, product learning, trust and loyalty. Fig. 2 shows the measurement model.

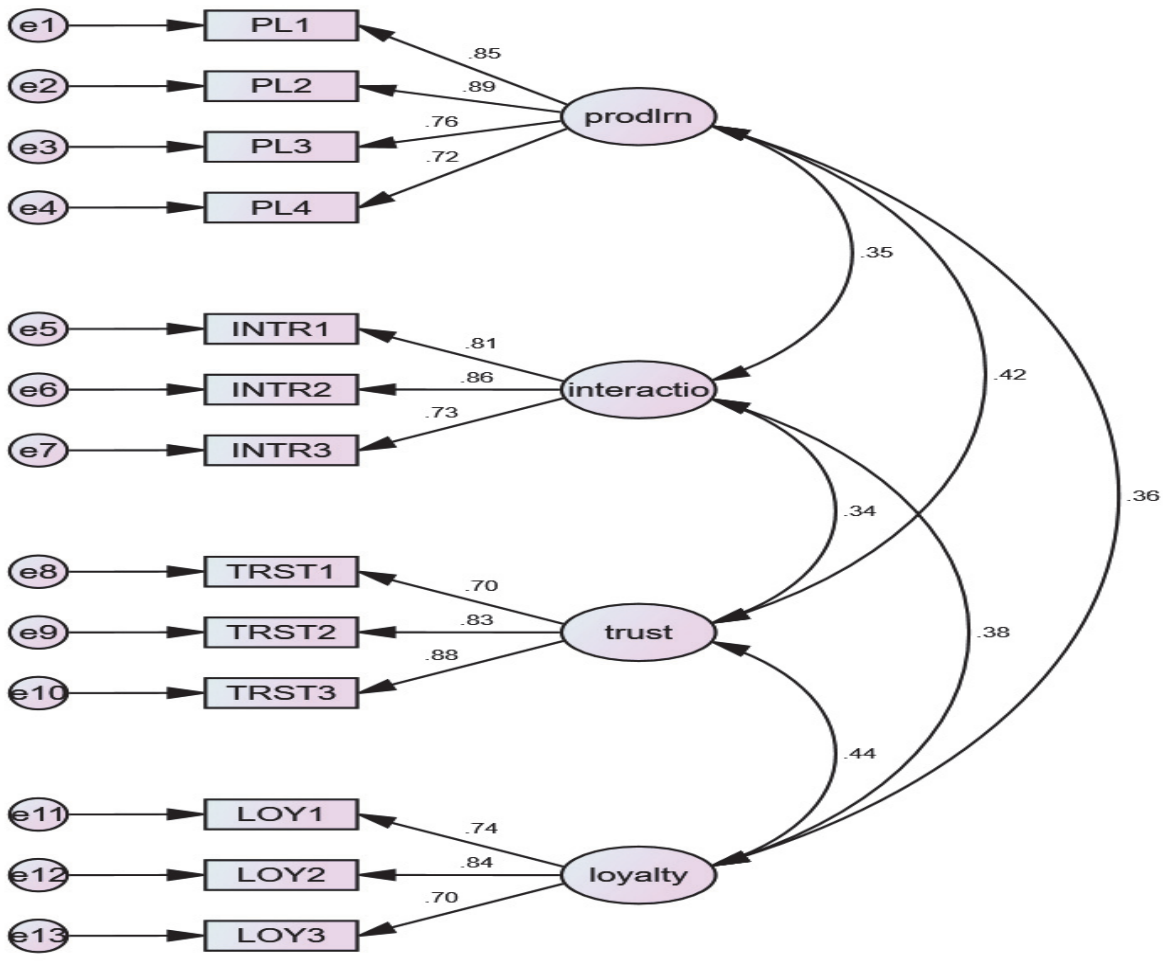

Fig. 2. Confirmatory Factor Analysis of the study variables 
Convergent validity is achieved as all items in the Confirmatory Factor Analysis have above the 0.70 threshold recommended by Hair (2010). While discriminant validity is checked through covariance values of less than 0.50 between the latent variables. Additionally the model fit indices for the model were deemed satisfactory as shown in Table 1 as follows,

Table 1

Goodness of fit indices for the measurement model

\begin{tabular}{llll}
\hline Measure & Estimate & Threshold & Interpretation \\
\hline Chi-square & 261.356 & -- & -- \\
Degrees of freedom & 59 & -- & -- \\
Relative Chi-square & 4.43 & Between 1 and 3 & Excellent \\
CMIN/DF & 4.43 & Between 1 and 3 & Excellent \\
CFI & 0.93 & $>0.95$ & Acceptable \\
SRMR & 0.063 & $<0.08$ & Excellent \\
RMSEA & 0.091 & $<0.06$ & Excellent \\
\hline
\end{tabular}

\subsection{Hypothesis testing}

After establishing the validity and reliability of the dataset, the next step involved creating a structural equation model to test the three main direct hypotheses as shown in Fig. 3 below.

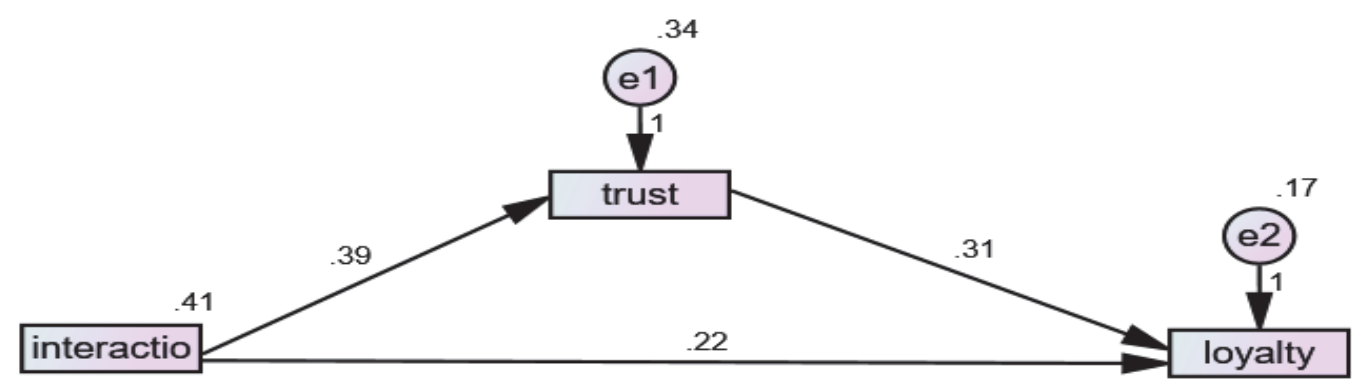

Fig. 3. Structural model

According to the results obtained from the structural model in Fig. 3, hypotheses 1-3 were tested and the results are shown in Table 2 as follows,

Table 2

Results of structural model hypotheses testing

\begin{tabular}{cccccc}
\hline & Independent & dependent & Std Beta & Sig & Result \\
\hline H1 & Interaction & Loyalty & .28 & $* * *$ & Supported \\
H2 & Interaction & Trust & .39 & $* * *$ & Supported \\
H3 & Trust & Loyalty & .40 & $* * *$ & Supported \\
\hline
\end{tabular}

***significance level $\mathrm{p}<0.01$

The structural model investigated here reveals three results: first, customer interaction on social media impact on customer loyalty towards hotels was significantly positive $(\beta=.28, \mathrm{p}<.001)$, which meant that hypothesis one $\left(\mathrm{H}_{1}\right)$ found empirical support. Second, customer interaction on social media impact on customer trust displayed for hotels was both positive and significant $(\beta=.39, \mathrm{p}<.000)$, which meant that hypothesis one $\left(\mathrm{H}_{2}\right)$ was empirically substantiated. Finally, customer trust had a significant and positive impact on the loyalty within hotel guests participating in this study $(\beta=.40, p<.000)$. Additionally, bootstrapping was conducted to test the mediation effect of the indirect path of customer interaction on 
social media through trust to evaluate its impact on customer loyalty to test hypothesis four. Bootstrapping was set to 2000 iterations, while bias-corrected intervals was set at $90 \%$ confidence interval. Results are shown in table below.

Table 3

Mediation analysis bootstrapping results

\begin{tabular}{lcccc}
\hline Path & Estimate & Lower & Upper & $\mathrm{P}$ \\
\hline Interaction-trust-loyalty & .12 & .09 & .16 & .00 \\
\hline
\end{tabular}

The results obtained indicate that trust mediates the relationship between customer interaction on social media platforms and loyalty, as a result $\mathrm{H}_{4}$ is empirically supported. Next the moderating effect of product learning on the relationship between customer interactions and trust was examined. This examination is shown in Fig. 4.

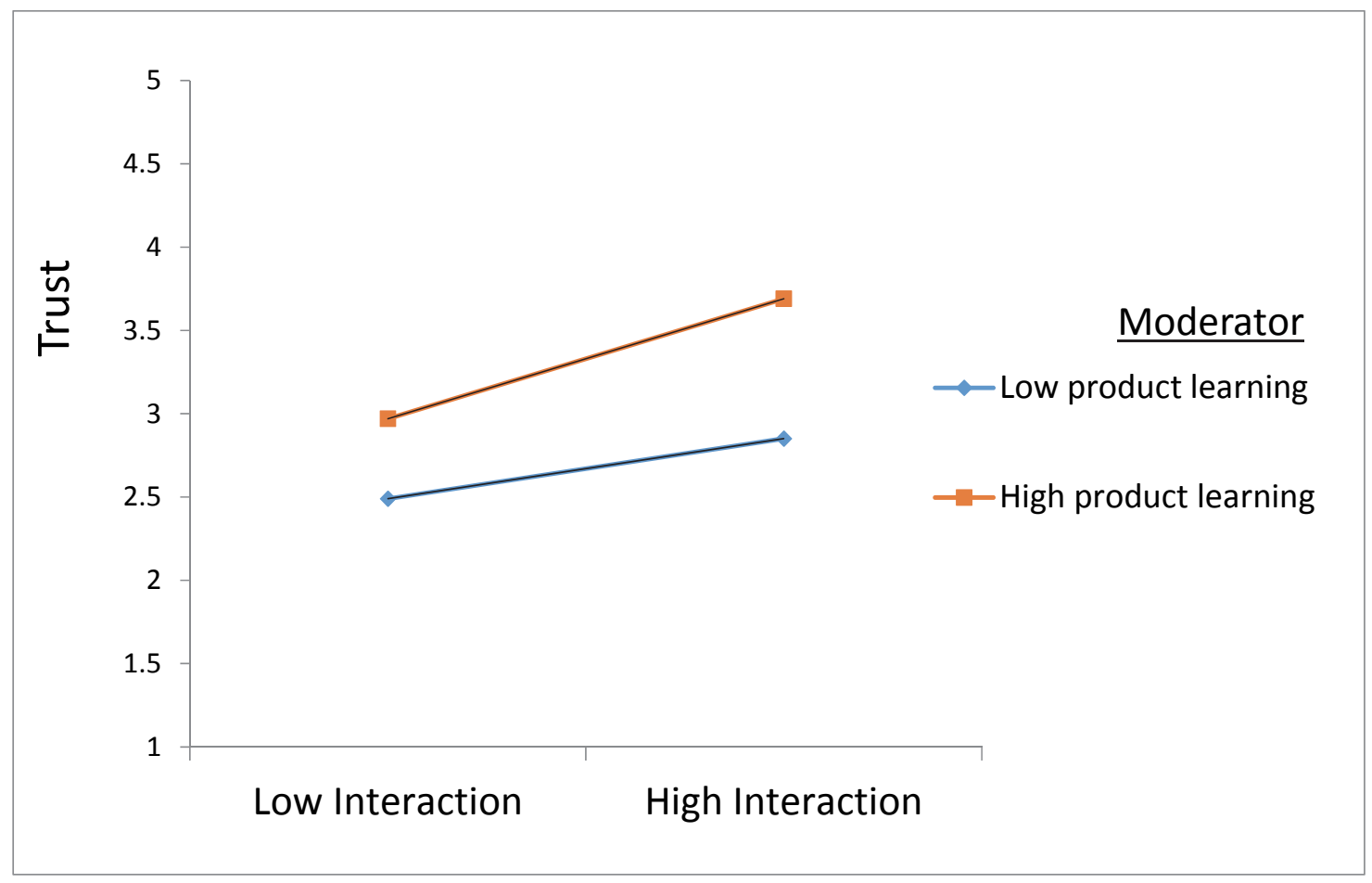

Fig. 4. Product learning moderating impact on the relationship between interaction and trust

The interaction effect was found to be significant $(\beta=.18, \mathrm{p}<.000)$, whereby the positive effect of product learning has a strengthening impact on the positive relationship between customer social media interaction and trust.

\section{Conclusion}

\section{1 implications for theory development}

By postulating and then conducting empirical investigation and testing a conceptual model, this research provides bases for future studies on customer interaction on social media platforms. To start with, this research represents an answer for calls to understand customer interactions effects through social media mediums on the customer attitudes and behaviors towards organizations. The primary research gap addressed here relates to two consumer related behaviors, namely; trust and loyalty. Through proving the existence of these relationship between customer interaction on one hand and trust and loyalty on the 
other, this work opens the door for more behavior or attitude related concepts to ne investigated to fully understand the effects of interaction on organizations.

\section{2 implications for practice}

This study provides important lessons for managers and hotel owners. First, interacting on social media with hotels does positively affect customers' loyalty and trust in the hotel services. Thus, investing in having social media accounts updated and relevant is financially justified as loyalty and trust among customers are translated into more turnover and profits for hotels. Additionally, providing information about the hotel services to customers on social media does enhance the transparency of service provider, thus having a strengthen effect on the consumer trust in the hotel. As a result, hotels are advised to provide as much information as possible regarding their services offerings to customers on social media platforms.

\section{3 limitations}

Academic studies in general propose suggestions that are limited by the nature and design of the study, and this study is no exception. First of all, this study was conducted in Cyprus northern coast area (Kyrenia). Hence, generalizations to other geographic locations should be done after replication studies are commissioned in these new settings. Second, there are some concerns associated with the moderation effect, since in the study reported here only one moderating factor was investigated. So, more boundary conditions variables should and must be considered to rule out the possibility of other factors having an impact that was not studied in this research.

\section{References}

Bilgihan, A., Cobanoglu, C., Nusair, K., Okumus, F., \& Bujisic, M. (2013). A quantitative study exploring the difference between gaming genre preferences. The Computer Games Journal, 2(1), 1940.

Boyd, D. M., \& Ellison, N. B. (2007). Social network sites: Definition, history, and scholarship. Journal of Computer-Mediated Communication, 13(1), 210-230.

Brass, D. J., Butterfield, K. D., \& Skaggs, B. C. (1998). Relationships and unethical behavior: A social network perspective. Academy of Management Review, 23(1), 14-31.

Caro, L. M., \& Roemer, E. (2006). Developing a multidimensional and hierarchical service quality model for the travel and tourism industry. University of Bradford, School of Management.

Chaudhuri, A., \& Holbrook, M. B. (2001). The chain of effects from brand trust and brand affect to brand performance: the role of brand loyalty. Journal of marketing, 65(2), 81-93.

Chiu, C. M., Huang, H. Y., \& Yen, C. H. (2010). Antecedents of trust in online auctions. Electronic Commerce Research and Applications, 9(2), 148-159.

Chung, N., \& Koo, C. (2015). The use of social media in travel information search. Telematics and Informatics, 32(2), 215-229.

Chen, C. M., Chen, S. H., \& Lee, H. T. (2013). Interrelationships between physical environment quality, personal interaction quality, satisfaction and behavioural intentions in relation to customer loyalty: The case of Kinmen's bed and breakfast industry. Asia Pacific Journal of Tourism Research, $18(3), 262-287$.

Grabner-Kräuter, S. (2009). Web 2.0 social networks: the role of trust. Journal of business ethics, 90(4), 505-522.

Habibi, M. R., Laroche, M., \& Richard, M. O. (2014). The roles of brand community and community engagement in building brand trust on social media. Computers in Human Behavior, 37, 152-161.

Harrigan, P., Evers, U., Miles, M., \& Daly, T. (2017). Customer engagement with tourism social media brands. Tourism Management, 59, 597-609.

Holmes, J. G. (1991). Trust and the appraisal process in close relationships. In W. H. Jones \& D. Perlman (Eds.). Advances in personal relationships (Vol. 2,pp. 57-104). London: Jessica Kingsley. 
Howat, G., Absher, J., Crilley, G., \& Milne, I. (1996). Measuring customer service quality in sports and leisure centres. Managing leisure, 1(2), 77-89.

Hsu, C. L., Liu, C. C., \& Lee, Y. D. (2010). Effect of commitment and trust towards micro-blogs on consumer behavioral intention: A relationship marketing perspective. International Journal of Electronic Business Management, 8(4).

Huang, Y., Basu, C., \& Hsu, M. K. (2010). Exploring motivations of travel knowledge sharing on social network sites: an empirical investigation of US college students. Journal of Hospitality Marketing \& Management, 19(7), 717-734.

Huang, S. L., \& Chen, C. T. (2018). How consumers become loyal fans on Facebook. Computers in Human Behavior, 82, 124-135.

Iryo, T., Yamabe, K., \& Asakura, Y. (2012). Dynamics of information generation and transmissions through a social network in non-recurrent transport behaviour. Transportation Research Part C: Emerging Technologies, 20(1), 236-251.

Jeppesen, L. B., \& Molin, M. J. (2003). Consumers as co-developers: Learning and innovation outside the firm. Technology Analysis \& Strategic Management, 15(3), 363-383.

Kim, H. W., Gupta, S., \& Koh, J. (2011). Investigating the intention to purchase digital items in social networking communities: A customer value perspective. Information \& Management, 48(6), 228234.

Kleijnen, M., Lievens, A., De Ruyter, K., \& Wetzels, M. (2009). Knowledge creation through mobile social networks and its impact on intentions to use innovative mobile services. Journal of Service Research, 12(1), 15-35.

Lerner, J., \& Tirole, J. (2002). Some simple economics of open source. The Journal of Industrial Economics, 50(2), 197-234.

McDougall, G. H., \& Levesque, T. (2000). Customer satisfaction with services: putting perceived value into the equation. Journal of Services Marketing, 14(5), 392-410.

Nambisan, S., \& Baron, R. A. (2010). Different roles, different strokes: Organizing virtual customer environments to promote two types of customer contributions. Organization Science, 21(2), 554572.

Nunnally, J. C., Bernstein, I. H., \& Berge, J. M. T. (1967). Psychometric theory (Vol. 226). New York: McGraw-hill.

Pavlou, P. A., Liang, H., \& Xue, Y. (2007). Understanding and mitigating uncertainty in online exchange relationships: A principal-agent perspective. MIS quarterly, 105-136.

Tussyadiah, I. P., \& Zach, F. J. (2012). The role of geo-based technology in place experiences. Annals of Tourism Research, 39(2), 780-800.

Wakefield, K. L., Blodgett, J. G., \& Sloan, H. J. (1996). Measurement and management of the sportscape. Journal of Sport Management, 10(1), 15-31.

Wang, Y. D., \& Emurian, H. H. (2005). An overview of online trust: Concepts, elements, and implications. Computers in Human Behavior, 21(1), 105-125.

Wasko, M. M., \& Faraj, S. (2005). Why should I share? Examining social capital and knowledge contribution in electronic networks of practice. MIS Quarterly, 29(1), 35-57.

Wellman, B., Salaff, J., Dimitrova, D., Garton, L., Gulia, M., \& Haythornthwaite, C. (1996). Computer networks as social networks: Collaborative work, telework, and virtual community. Annual Review of Sociology, 22(1), 213-238.

Yoo, K. H., Lee, Y., Gretzel, U., \& Fesenmaier, D. R. (2009). Trust in travel-related consumer generated media. Information and Communication Technologies in Tourism 2009, 49-59.

Zeithaml, V. A., Berry, L. L., \& Parasuraman, A. (1996). The behavioral consequences of service quality. Journal of Marketing, 60(2), 31-46. 


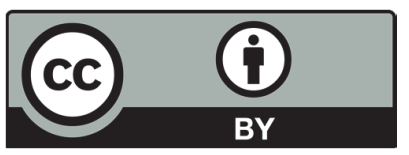

(C) 2019 by the authors; licensee Growing Science, Canada. This is an open access article distributed under the terms and conditions of the Creative Commons Attribution (CCBY) license (http://creativecommons.org/licenses/by/4.0/). 